\title{
A Weighted Goal Programming Model for the DASH Diet Problem: Comparison with the Linear Programming DASH Diet Model
}

\author{
Anayo Charles Iwuji ${ }^{1}$, Emeka Uchendu Agwu ${ }^{2}$ \\ ${ }^{1}$ Department of Statistics, Michael Okpara University of Agriculture, Umudike, Nigeria \\ ${ }^{2}$ Department of Mathematics, Michael Okpara University of Agriculture, Umudike, Nigeria \\ Email:iwuji.charles@mouau.edu.ng,agwuemekauchendu@gmail.com
}

How to cite this paper: Iwuji, A.C. and Agwu, E.U. (2017) A Weighted Goal Programming Model for the DASH Diet Problem: Comparison with the Linear Programming DASH Diet Model. American Journal of Operations Research, 7, 307-322. https://doi.org/10.4236/ajor.2017.75023

Received: August 24, 2017

Accepted: September 25, 2017

Published: September 28, 2017

Copyright (c) 2017 by authors and Scientific Research Publishing Inc. This work is licensed under the Creative Commons Attribution International License (CC BY 4.0).

http://creativecommons.org/licenses/by/4.0/

(c) (i) Open Access

\begin{abstract}
A Linear Programming DASH diet model for persons with hypertension has previously been formulated and daily minimum cost diet plans that satisfy the DASH diets' tolerable intake level of the nutrients for $1500 \mathrm{mg}$ a day Sodium level and different daily calorie levels were obtained using sample foods from the DASH diet eating plan chart. But the limitation in the use of linear programming model in selecting diet plans to meet specific nutritional requirements which normally results in the oversupply of certain nutrients was evident in the linear programming DASH diet plan obtained as the nutrient level of the diet plans obtained had wide deviations of from the DASH diets' tolerable upper and lower intake level for the given calorie and sodium levels. Hence the need for a model that gives diet plans with minimized nutrients' level deviations from the DASH diets' tolerable intake level for different daily calorie and sodium level at desired cost. A weighted Goal Programming DASH diet model that minimizes the daily cost of the DASH eating plan as well as deviations of the diets' nutrients content from the DASH diet's tolerable intake levels is hereby presented in this work. The formulated weighted goal programming DASH diet model is further illustrated using chosen sample foods from the DASH food chart as used in the work on the linear programming DASH diet model for a $1500 \mathrm{mg}$ sodium level and 2000 calories a day diet plan as well as for 1800, 2200, 2400, 2600, 2800 and 3000 daily calorie levels. A comparison of the DASH nutrients' composition of the weighted Goal Programming DASH diet plans and those of the linear programming DASH diet plans were carried out at this sodium level and the different daily calorie levels. It was evident from the results of the comparison that the weighted goal programming DASH diet plans has minimized deviations from the DASH diet's tolerable intake levels than those of the linear programming DASH diet plans.
\end{abstract}




\section{Keywords}

DASH (Dietary Approaches to Stop Hypertension) Diet Model, Hypertension Diet Model, Minimum Nutrient Deviation Diet Plan, Weighted Goal Programming Diet Model, Linear and Goal Programming Comparison

\section{Introduction}

The DASH eating plan has been shown by research to prevent or lower high blood pressure. The DASH heart healthy daily eating plan requires foods that have low sodium, saturated fat, total fat and cholesterol nutrient content while rich in potassium, magnesium, calcium and fiber: see [1]. These eight mentioned nutrients which the DASH diet tends to decrease (i.e. sodium, total fat, saturated fat, cholesterol) and increase (i.e. potassium, magnesium, calcium, fiber) are referred to as the "DASH nutrients" in this work. The DASH diet problem involves the challenge of having daily eating plans that meets the DASH diets' nutrients tolerable intake levels at a targeted budget based on the desired daily calorie and sodium levels by concerned persons in order to reduce high blood pressure. A Linear Programming (LP) DASH diet model for persons with hypertension has been formulated in a previous research in which daily minimum cost diet plans that satisfy the DASH diets' nutrients tolerable target intake level for $1500 \mathrm{mg}$ sodium level and different daily calorie levels were obtained using sample foods of the DASH diet eating plan chart: see [2]. But the linear programming DASH diet model just like every linear programming model had its limitation. Besides, having just a single objective which was to obtain a daily minimum cost diet plan, there were large deviation of some nutrients from the DASH diets' nutrients tolerable intake level for $1500 \mathrm{mg}$ sodium level as was seen in the work on the LP DASH diet model. There was excess fiber, calcium, magnesium and potassium nutrients content in the LP diet plans as compared to their DASH tolerable intake levels. As we know, Nutrients when taken in excess have harmful effects. Excess fiber in a diet can cause several health problems like cramping, diarrhea, intestinal blockage while excess potassium on the other hand causes hyperkalemia among other side effects. Also excess calcium causes constipation, depression and fatigue among other side effects while excess magnesium is known to cause irregular heartbeat, low blood pressure, slow breathing and even death. Hence the need for a better model that give diet plans with minimized deviations from the DASH diets' tolerable intake levels for different daily calorie level diet plans at a desired cost. The goal programming technique is an appropriate method for achieving nutritional balance in selected diets [3] as it is also a popular theoretical method for dealing with multiple objective decision-making problems [4]. It provides a more systematic approach to the problem of balancing the supply of nutrients in a selection of foods. Goal Programming (GP) is a tool proposed as a model and approach for the analysis of 
problems involving multiple, conflicting objectives and is applied in systems for which these varieties of conflicting, non-commensurable goals might be impossible to satisfy exactly and thus an attempt is made to minimize the sum of the absolute values of deviations from such goals [5]. Hence goal programming tends to obtain an efficient solution since the solution might not be optimum with respect to all the conflicting objectives [6]. Weights are assigned to some deviational variables in the objective function to better reflect the importance and desirability of such deviations from the various goals.

The goal programming technique has been used by many researchers to model diet problems. [7] presented the goal programming technique as a method of obtaining nutritional balance in human diet as against the linear programming approach which is difficult to achieve this nutritional balance with. They illustrated this comparison using 150 food raw materials to satisfy the daily nutritional requirements of Thais. The result obtained showed a marked improvement of the goal programming results over that of linear programming. [8] also developed a 4-phase approach for designing optimal population-specific food-based Complementary Feeding Recommendations (CFRs) in which the goal programming techniques were used to select an optimal diet which aimed at providing a desired nutrient content with respect to habitual diet patterns and cost. A hypothetical example was used to illustrate the approach. An optimal food consumption plan for the rural households, in Kwara State Nigeria, was developed using the food security index and the linear goal programming model in which the result obtained showed that about $65.45 \%$ of the rural households were food insecure: see [9]. [10] developed a goal programming nutrition optimization model to meet daily nutrient needs of the reference woman and the reference man subject to available household budget. The objective was to minimize deviations from the defined micronutrients and macronutrients needs as well as from food cost. The model constraints consist of the nutrient needs determined according to World Health Organization (WHO) standards and the decision variables were used food items based on a survey of 50 households in Bosnia and Herzegovina. An optimal food intake plan that minimized deviations from the defined goals was obtained. A methodological insight into the several achievement functions of diet models based on goal programming as valuable tools in designing diets that comply with nutrition, palatability and cost constraints was presented by [11]. They further described the extended goal programming (EGP) achievement function, which enables the decision maker to use either a MinSum achievement function (which minimizes the sum of unwanted deviations), or a compromise between both. The MinSum achievement function were found to give rise to solutions that are sensitive to weight changes and that pile all unwanted deviations on a limited number of nutritional constraints. [12] on the other hand focused on the human diet problem in fuzzy environment. The approach dealt with multi-objective fuzzy linear programming problem using a fuzzy programming technique for its solution. Result obtained 
showed some uncertainties about how factors of nutrition diet-including taste and price, amounts of nutrients and their intake-affects diet quality, making the proposed model more realistic. Meanwhile, [13] presented a method and tool for optimizing beef-fattening diets. The approach presented was an example of how a combination of mathematical programming techniques might be applied to prepare a user-friendly tool for optimal ration formulations. A spreadsheet was constructed from two modules based on mathematical deterministic programming techniques. To obtain an estimate of the magnitude of cost that any be incurred, the first module utilizes a linear program for least-cost ration formulation. The resulting value is then targeted as a cost goal in the second module. This is supported by weighted goal programming with a penalty function. An algorithm to produce a list of food items that meets specific nutritional requirements was generated in [14]. With the algorithm, each nutrient received a score based on the amount of nutrients contained in the food list in relation to the Lower Bound Amount (LBA), Ideal Amount (IA) and Upper Bound Amount (UBA) necessary for the human body to thrive and these scores were aggregated to give the meal plan an overall score. [15] explored shared explanatory models (EM) of high blood pressure(HBO)/hypertension (HTN) using systematic data collection and analysis methods from cognitive anthropology. Quantitative and qualitative methods were used to discover the cultural knowledge of HBP/HTN shared by Medicare-eligible older adults in Los Angeles, some of whom had been diagnosed with HTN and some whom had not. [16] presented a linear and goal programming optimization model for determining and analyzing the food basket in Bosnia and Herzegovina in terms of adequate nutritional needs according to WHO and World Bank recommendations. Based on the official food basket, Linear Programming modeling was used to provide a more efficient solution for the food basket while a Goal Programming model was also developed in order to minimize deviations from nutrients constraints for a fixed budget. Meanwhile in this paper we present the Weighted Goal Programming model for the DASH diet problem for persons with hypertension as a more systematic approach in minimizing the deviations of the nutrient content of the daily eating plans from the targeted DASH diet nutrients' tolerable intake level as well as showing it is a better model compared to the Linear programming DASH diet model.

\section{Methodology}

\subsection{The Linear Programming DASH Diet Model}

The linear programming DASH diet model is given as follows:

$$
\text { Minimize } D C=C_{1} X_{1}+C_{2} X_{2}+C_{3} X_{3}+\cdots+C_{n} X_{n}
$$

Subject to the Constraints

$$
a_{11} X_{1}+a_{12} X_{2}+a_{13} X_{3}+\cdots+a_{1 n} X_{n} \leq R_{1 c}
$$

(Constraint on total fat) 


$$
a_{21} X_{1}+a_{22} X_{2}+a_{23} X_{3}+\cdots+a_{2 n} X_{n} \leq R_{2 c}
$$

(Constraint on sodium)

$$
a_{31} X_{1}+a_{32} X_{2}+a_{33} X_{3}+\cdots+a_{3 n} X_{n} \leq R_{3 c}
$$

(Constraint on cholesterol)

$$
a_{41} X_{1}+a_{42} X_{2}+a_{43} X_{3}+\cdots+a_{4 n} X_{n} \leq R_{4 c}
$$

(Constraint on saturated fat)

$$
a_{51} X_{1}+a_{52} X_{2}+a_{53} X_{3}+\cdots+a_{5 n} X_{n} \geq R_{5 c}
$$

(Constraint on calcium)

$$
a_{61} X_{1}+a_{62} X_{2}+a_{63} X_{3}+\cdots+a_{6 n} X_{n} \geq R_{6 c}
$$

(Constraint on magnesium)

$$
a_{71} X_{1}+a_{72} X_{2}+a_{73} X_{3}+\cdots+a_{7 n} X_{n} \geq R_{7 c}
$$

(Constraint on fiber)

$$
a_{81} X_{1}+a_{82} X_{2}+a_{83} X_{3}+\cdots+a_{8 n} X_{n} \geq R_{8 c}
$$

(Constraint on potassium)

$$
a_{91} X_{1}+a_{92} X_{2}+a_{93} X_{3}+\cdots+a_{9 n} X_{n}=R_{c}
$$

(Constraint on calorie)

$$
\begin{aligned}
& X_{j} \geq S_{L j c} \\
& X_{j} \leq S_{H j c}
\end{aligned}
$$

where $X_{1}, X_{2}, X_{3}, \cdots, X_{n} \geq 0$,

$j=1,2,3, \cdots, n$, where $j$ is number of food items;

$i=1,2,3, \cdots, 9$, where $i$ is number of nutrients.

where $D C=$ Diet Cost,

$a_{11}, a_{12}, a_{13}, \cdots, a_{8 n}$ are the content of the "DASH nutrients" in the foods.

$R_{1 c}, R_{2 c}, R_{3 c}$ and $R_{4 c}$ are the Tolerable Upper Intake Level for Total fat, Sodium Cholesterol and Saturated fat respectively for calorie level $c$.

$R_{5 c}, R_{6 c}, R_{7 c}$ and $R_{8 c}$ are the Tolerable Lower Intake Level for Calcium, Magnesium, Fiber and Potassium respectively for calorie level $c$.

$R_{c}$ is the Calorie level.

$S_{L j c}$ is the estimated Least number of daily Servings of food item $j$ for calorie level $c$.

$S_{H j c}$ is the estimated Highest number of daily Servings of food item $j$ for calorie level $c$.

\subsection{Weighted Goal Programming Model}

The Weighted Goal programming model is used when the decision maker is interested in minimizing the deviations of set goals of relatively equal importance and assigns weights as coefficients to the deviational variables in the objective function to better reflect their importance and desirability of the deviations from the various goals. [17] stated the weighted Goal Programming model as: 


$$
\text { Minimize } Z=\sum_{i=1}^{m}\left(w_{i}^{+} d_{i}^{+}+w_{i}^{-} d_{i}^{-}\right)
$$

Subject to the constraints

Goal constraints: $\sum_{j=1}^{n} a_{i j} x_{j}+d_{i}^{-}-d_{i}^{+}=b_{i}$ for $i=1, \cdots, m$

System constraints: $\sum_{j=1}^{n} a_{i j} x_{j}=b_{i}$

With $d_{i}^{+}, d_{i}^{-}, x_{j} \geq 0$, for $i=1, \cdots, m$ and $j=1, \cdots, n$

where

$Z$ is the objective function,

$d_{i}^{-}$and $d_{i}^{+}$are the negative and positive deviational variables (underachievement and overachievement) in goal $i$,

$w_{i}^{-}$and $w_{i}^{+}$are non-negative constants representing the relative weights to be assigned to the respective positive and negative deviation variables,

$a_{i j}$ is the coefficient associated with variable $j$ in goal $i$.

With $i=1, \cdots, m$ and $j=1, \cdots, n$.

\subsection{The Dash Eating Plan}

The DASH eating plan is rich in fruits, vegetables, fat free or low-fat milk and milk products, whole grains, fish, poultry, beans, seeds and nuts. It also contains less salt and sodium, sweets, added sugar, and sugar-containing beverages, fats and red meats than most typical diets. The DASH eating plan for each individual according to the "Guide to lowering your Blood Pressure with DASH" depends on the number of calories that individual is allowed each day. The calorie levels which includes 1800, 2000, 2200, 2400, 2600, 2800 and 3000 calories a day depends on the age and activity level of the individual. Different calorie needs for each of the activity levels and for different ages for both males and females is shown in the appendices. The DASH eating plan is also based on recommended levels of daily sodium intake. This includes the 2300 and 1500 milligrams Sodium levels that DASH allows each day.

\subsection{Weighted Goal Programming DASH Diet Model}

The decision variables for the weighted Goal Programming DASH diet model are $x_{1}, x_{2}, x_{3}, \cdots, x_{n}$ which represents the daily number of servings of foods $1,2,3, \cdots, n$ in the diet plan.

The target goals to be achieved include:

- Goal 1 (Cost goal): Minimize the overachievement of the daily target cost of the diet, $C_{g}$.

- Goal 2 (Sodium nutrient goal): Minimize the overachievement of the Tolerable Intake Level of sodium $\left(S_{g}\right)$, in milligrams $(\mathrm{mg})$.

- Goal 3 (Cholesterol goal): Minimize the overachievement of the Tolerable Intake Level of cholesterol, ( $\left.C O L_{m g}\right)$, in milligrams (mg).

- Goal 4 (Total fat goal): Minimize the overachievement of the Tolerable Intake Level of total fat $\left(T F_{g}\right)$, in grams $(\mathrm{g})$.

- Goal 5 (Calorie goal): Attain the allowed daily calorie level ( $\left.C A L O_{g}\right)$. 
- Goal 6 (Saturated fat goal): Minimize the overachievement of the Tolerable Intake Level of saturated fat $\left(S F_{m g}\right)$, in milligrams $(\mathrm{mg})$.

- Goal 7 (Magnesium goal): Minimize the underachievement of the Tolerable Intake Level of magnesium ( $\left.M_{m g}\right)$, in milligrams ( $\mathrm{mg}$ ).

- Goal 8 (Fiber goal): Minimize the underachievement of the Tolerable Intake Level of fiber $\left(F I B_{g}\right)$, in grams $(g)$.

- Goal 9 (Potassium goal): Minimize the underachievement of the Tolerable Intake Level of potassium, $P_{m g}$, in milligrams (mg).

- Goal 10 (Calcium goal): Minimize the underachievement of the Tolerable Intake Level of calcium, $C A L_{m g}$, in milligrams (mg).

Because we don't have the same unit of measurements for the different goals, hence the variables in the objective function will represent percentage deviation rather than absolute deviation.

So the objective function that minimizes the sum of the percentage deviations from the targets is given as;

$$
\text { Minimize } \begin{aligned}
D= & w_{C}^{+} \frac{d_{C}^{+}}{b_{C}} \cdot \frac{100}{1}+w_{S}^{+} \frac{d_{S}^{+}}{b_{S}} \cdot \frac{100}{1}+w_{c o l}^{+} \frac{d_{c o l}^{+}}{b_{c o l}} \cdot \frac{100}{1}+w_{T F}^{+} \frac{d_{T F}^{+}}{b_{T F}} \cdot \frac{100}{1} \\
& +w_{S F}^{+} \frac{d_{S F}^{+}}{b_{S F}} \cdot \frac{100}{1}+w_{M}^{-} \frac{d_{M}^{-}}{b_{M}} \cdot \frac{100}{1}+w_{F i b}^{-} \frac{d_{F i b}^{-}}{b_{F i b}} \cdot \frac{100}{1}+w_{P}^{-} \frac{d_{P}^{-}}{b_{P}} \cdot \frac{100}{1} \\
& +w_{C a l}^{-} \frac{d_{C a l}^{-}}{b_{C a l}} \cdot \frac{100}{1}+\left(w_{\text {calo }}^{-} \frac{d_{\text {calo }}^{-}}{b_{\text {calo }}}+w_{\text {calo }}^{+} \frac{d_{\text {calo }}^{+}}{b_{\text {calo }}}\right) \cdot \frac{100}{1}
\end{aligned}
$$

Subject to the constraints

$$
c_{1} x_{1}+c_{2} x_{2}+c_{3} x_{3}+\cdots+c_{n} x_{n}+(0) d_{c}^{-}+(1) d_{c}^{+}=C_{(\$)}
$$

(Cost goal constraint in Dollars)

$$
a_{11} x_{1}+a_{12} x_{2}+a_{13} x_{3}+\cdots+a_{1 n} x_{n}+(0) d_{s}^{-}-(1) d_{s}^{+}=S_{(g)}
$$

(Sodium goal constraint in grams)

$$
a_{21} x_{1}+a_{22} x_{2}+a_{23} x_{3}+\cdots+a_{2 n} x_{n}+(0) d_{c o l}^{-}-(1) d_{c o l}^{+}=C O L_{(m g)}
$$

(Cholesterol goal constraint in milligrams)

$$
a_{31} x_{1}+a_{32} x_{2}+a_{33} x_{13}+\cdots+a_{3 n} x_{n}+(0) d_{t f}^{-}-(1) d_{t f}^{+}=T F_{(g)}
$$

(Total fat goal constraint in grams)

$$
a_{41} x_{1}+a_{42} x_{2}+a_{43} x_{3}+\cdots+a_{4 n} x_{n}+(0) d_{s f}^{-}-(1) d_{s f}^{+}=S F_{(m g)}
$$

(Saturated fat goal constraint in milligrams)

$$
a_{51} x_{1}+a_{52} x_{2}+a_{53} x_{3}+\cdots+a_{5 n} x_{n}+(1) d_{M}^{-}-(0) d_{M}^{+}=M_{(m g)}
$$

(Magnesium goal constraint in milligrams)

$$
a_{61} x_{1}+a_{62} x_{2}+a_{63} x_{3}+\cdots+a_{6 n} x_{n}+(1) d_{f i b}^{-}-(0) d_{f i b}^{+}=F^{\prime g} B_{(g)}
$$

(Fiber goal constraint in grams) 


$$
a_{71} x_{1}+a_{72} x_{2}+a_{73} x_{3}+\cdots+a_{7 n} x_{n}+(1) d_{P}^{-}-(0) d_{P}^{+}=P_{(m g)}
$$

(Potassium goal constraint in milligrams)

$$
a_{81} x_{1}+a_{82} x_{2}+a_{83} x_{3}+\cdots+a_{8 n} x_{n}+(1) d_{C a}^{-}-(0) d_{C a}^{+}=C A_{(m g)}
$$

(Calcium goal constraint in milligrams)

$$
a_{91} x_{1}+a_{92} x_{2}+a_{93} x_{3}+\cdots+a_{9 n} x_{m}+(0) d_{\text {calo }}^{-}+(1) d_{\text {calo }}^{+}=C A L O
$$

(Calorie goal Constraint)

With $d_{C}^{+}, d_{S}^{+}, d_{c o l}^{+}, d_{T F}^{+}, d_{S F}^{+}, d_{M}^{-}, d_{F i b}^{-}, d_{P}^{-}, d_{C a l}^{-}$and $d_{\text {calo }}^{+}, d_{c a l o}^{-} \geq 0$ where:

$d_{C}^{+}, d_{S}^{+}, d_{c o l}^{+}, d_{t f}^{+}, d_{s f}^{+}, d_{M}^{+}, d_{f i b}^{+}, d_{P}^{+}, d_{C a}^{+}, d_{c a l o}^{+}$and $d_{C}^{-}, d_{S}^{-}, d_{c o l}^{-}, d_{t f}^{-}, d_{s f}^{-}, d_{M}^{-}, d_{f i b}^{-}, d_{P}^{-}, d_{C a}^{-}, d_{c a l o}^{-} \geq 0$ represents the overachievements and under achievements respectively of the cost, sodium, cholesterol, total fat, saturated fat, magnesium, fiber, potassium, calcium and calorie level,

$w_{C}^{+}, w_{S}^{+}, w_{C o l}^{+}, w_{T F}^{+}, w_{S F}^{+}, w_{M}^{-}, w_{F i b}^{-}, w_{P}^{-}, w_{C a l}^{-}, w_{\text {Calo }}^{+}$and $w_{C a l o}^{+}$are the weights assigned to the respective overachievements and under achievements of the diet cost, DASH nutrients and calorie level.

Weights are assigned to indicate desirable and undesirable deviations. Weights of " 1 " are assigned to deviations that are undesirable in the model while weights of " 0 " are assigned to deviations that are desirable in the model [18]. Hence we will assign weights of 1 to the overachievement of the cost target, the Tolerable Intake levels sodium, cholesterol, total fat, saturated fat and calorie goals and also to the underachievement of magnesium, fiber, potassium, calcium and calorie goals. This is because it is undesirable to overachieve and underachieve their target levels respectively as it against the intents of the DASH eating plan for reducing hypertension.

$b_{C}, b_{S}, b_{C o l}, b_{T F}, b_{M}, b_{F i b}, b_{P}, b_{C a l}$ and $b_{\text {Calo }}$ are the target values of the diet cost, DASH nutrients and calorie level respectively.

$a_{i j}=$ Quantity of ith DASH nutrient in $j$ th food (in $g$ or $m g$ depending on the nutrient).

with $i=1,2, \cdots, 8$ and $j=1,2, \cdots, n$.

$a_{9 j}=$ Calorie level of $\mathrm{jth}$ food (in calorie)

$C_{j}$, cost of 1 serving of $j$ th food.

$x_{j}=$ is the number of servings of food $\mathrm{j}$ in the diet plan.

$C_{g}$ is the budgeted cost of the eating plan.

$S_{g}, C O L_{g}, T F_{g}$ and $S F_{g}$ are the Tolerable target level of Sodium, Cholesterol, Total Fat and Saturated Fat respectively in the days' diet plan while $M_{g}$, $F I B_{g}, P 0_{g}$ and $C A L C_{g}$ are the tolerable target level of magnesium, fiber, potassium and calcium intake level respectively in the days' diet plan.

\section{Data Illustration of the Weighted Goal Programming DASH Diet Model}

The formulated weighted goal programming DASH diet model will be illustrated 
using the same data of selected food items from the DASH sample food chat and their cost per serving as used in work by [2]. The weighted Goal Programming DASH Diet plan for about 2000 calories a day with 1500 milligrams sodium level is considered in this model illustration where the targeted Tolerable Intake level of the nutrients is based on the attained nutrients level of a sample menu for 1500 milligrams sodium level and 2000 calories a day DASH eating plan as shown in the appendices. The formulated weighted Goal Programming DASH diet model with goals of attaining the desired daily cost of eating plan as well as attainment of the targeted Tolerable Intake Level of the nutrients is also presented in the appendices. Meanwhile the sufficient weighted Goal programming eating plan using the sample food items for a 1500 milligrams sodium level and about 2000 calories a day is presented in Table 1 below. Weights of one (1) are assigned to those deviational variables in which deviation in those direction are being avoided. The sufficient Weighted Goal programming DASH diet model was compared with that of the Linear programming DASH diet model with respect to their deviations from the Tolerable target Intake Level of the DASH nutrients.

The first part of Table 1 shows the Weighted Goal Programming daily diet plan for 2000 daily calories and 1500mg sodium level. The second part of

Table 1. Weighted goal programming daily diet plan for 2000 calorie-a-day and $1500 \mathrm{mg}$ sodium level and comparison of its DASH nutrients' composition with that of the linear programming DASH diet model with respect to DASH nutrients' tolerable intake level.

\begin{tabular}{|c|c|c|c|c|c|c|c|}
\hline \multicolumn{2}{|c|}{$\begin{array}{l}\text { Weighted Goal Programming daily } \\
\text { diet plan for } 2000 \text { daily calories and } \\
1500 \mathrm{mg} \text { sodium levels. }\end{array}$} & \multicolumn{6}{|c|}{$\begin{array}{l}\text { Comparison of the "DASH nutrients" composition of daily eating plans of the Weighted GP } \\
\text { model and the LP DASH diet model. }\end{array}$} \\
\hline Foods & $\begin{array}{l}\text { Daily } \\
\text { serving } \\
\text { sizes }\end{array}$ & Nutrients & $\begin{array}{l}\text { Tolerable } \\
\text { intake target } \\
\text { level of } \\
\text { nutrients }\end{array}$ & $\begin{array}{c}\text { Nutrient } \\
\text { composition } \\
\text { of weighted } \\
\text { GP model diet } \\
\text { plan }\end{array}$ & $\begin{array}{c}\% \\
\text { Deviation } \\
\text { from } \\
\text { nutrient } \\
\text { target }\end{array}$ & $\begin{array}{l}\text { Nutrient } \\
\text { composition } \\
\text { of LP model } \\
\text { diet plan }\end{array}$ & $\begin{array}{c}\% \\
\text { Deviation } \\
\text { from } \\
\text { nutrient } \\
\text { target }\end{array}$ \\
\hline Carrot (cut up) & 0 serving & Total fat & $68 \mathrm{~g}$ & $68 \mathrm{~g}$ & $0 \%$ & $24.80 \mathrm{~g}$ & $63.5 \%$ \\
\hline $\begin{array}{l}\text { Groundnut } \\
\text { (boiled, without salt) }\end{array}$ & 2.8 servings & Sodium & $1500 \mathrm{mg}$ & $1500 \mathrm{mg}$ & $0 \%$ & $1220.8 \mathrm{mg}$ & $18.6 \%$ \\
\hline $\begin{array}{c}\text { Bread } \\
\text { (whole wheat) }\end{array}$ & 11 servings & Cholesterol & $129 \mathrm{mg}$ & $129 \mathrm{mg}$ & $0 \%$ & $27 \mathrm{mg}$ & $79.1 \%$ \\
\hline $\begin{array}{l}\text { Sweet Potato } \\
\text { (boiled, without salt) }\end{array}$ & 0 serving & $\begin{array}{l}\text { Saturated } \\
\text { Fat }\end{array}$ & $16 \mathrm{~g}$ & $16 \mathrm{~g}$ & $0 \%$ & $7.55 \mathrm{~g}$ & $52.8 \%$ \\
\hline Milk (low fat, skimmed) & 3.9 servings & Calcium & $1334 \mathrm{mg}$ & $1334 \mathrm{mg}$ & $0 \%$ & $1334.2 \mathrm{mg}$ & $0.01 \%$ \\
\hline Orange & 0 serving & Magnesium & $542 \mathrm{mg}$ & $542 \mathrm{mg}$ & $0 \%$ & $542.8 \mathrm{mg}$ & $0.1 \%$ \\
\hline Watermelon & 39.7 servings & Fiber & $34 \mathrm{~g}$ & $33.09 \mathrm{~g}$ & $2.7 \%$ & $90.74 \mathrm{~g}$ & $166.9 \%$ \\
\hline $\begin{array}{l}\text { Fish (grilled, } \\
\text { without salt) }\end{array}$ & 0.02 serving & Potassium & $4721 \mathrm{mg}$ & 4721 & $0 \%$ & $8502.2 \mathrm{mg}$ & $80.1 \%$ \\
\hline \multirow[t]{2}{*}{ Cost of eating plan } & $\mathrm{N} 932.97$ & Calorie level & $\begin{array}{l}\text { About } 2000 \\
\text { Calories }\end{array}$ & 2000 & $0 \%$ & 2000.2 & $0.1 \%$ \\
\hline & & $\begin{array}{l}\text { Target cost } \\
\text { of daily } \\
\text { eating plan }\end{array}$ & $\begin{array}{l}\text { About } 945 \\
\text { Naira }\end{array}$ & $\begin{array}{l}932.97 \\
\text { Naira }\end{array}$ & $1.3 \%$ & $\begin{array}{l}\text { N944.41 } \\
\text { Naira }\end{array}$ & $0.06 \%$ \\
\hline
\end{tabular}


Table 1 shows the comparison of the deviations of the nutrients content of the Weighted GP DASH diet model with those of the LP DASH diet model from the targeted DASH nutrients' tolerable intake level for 2000 daily calorie and 1500 mg sodium levels. We can see in the comparison that there is deviation in the weighted Goal Programming model eating plan only for Fiber while the tolerable intake level nutrient target were met for the other DASH nutrients. On the other hand, for the Linear Programming DASH model eating plan we can see large deviations in the nutrient content of Total fat, Sodium, Cholesterol, Saturated fat, Fiber and Potassium from their DASH targeted tolerable intake nutrient levels.

Table 2 shows the comparison of the nutrient content of the Weighted GP

Table 2. Comparison of the "DASH nutrients" composition between the weighted goal programming DASH diet model and the linear programming DASH diet model eating plans for different daily calorie levels.

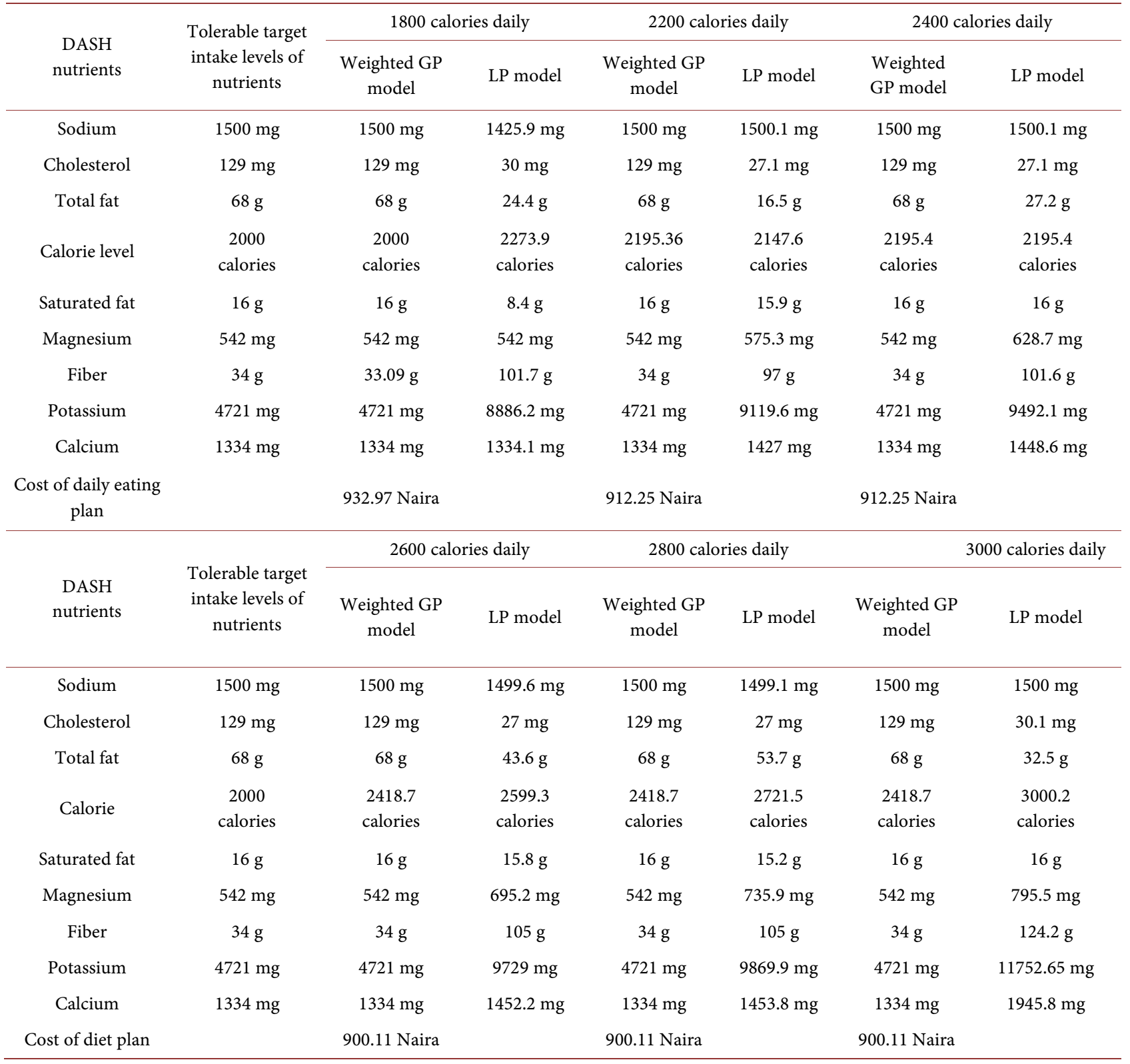


DASH diet model and that of the LP DASH diet model with respect to the DASH nutrients tolerable intake level for $1500 \mathrm{mg}$ sodium level for 1800, 2200, $2400,2600,2800$ and 3000 calorie levels. As in the case of the comparison of the 2000 daily calorie level we see that the Weighted Goal programming model gives eating plans with minimized nutrient deviations from the targeted DASH nutrients' tolerable target levels while in the cases of the Linear programming model there are very large nutrient deviations from targeted DASH nutrients' tolerable intake levels.

\section{Conclusion}

The Weighted Goal Programming DASH diet model that minimizes the daily cost of the DASH eating plan as well as deviations of the daily diet plans' nutrient content from the targeted DASH diet's tolerable intake levels has been formulated. It was further illustrated using the chosen sample foods from the DASH food chart for $1500 \mathrm{mg}$ sodium level and 2000 calories a day diet plan and then also for 1800, 2200, 2400, 2600, 2800 and 3000 calorie levels. The "DASH nutrients" composition between the Weighted Goal Programming DASH diet model and the Linear Programming DASH diet model eating plans for different daily calorie levels was compared. From the comparison of the percentage deviation of the nutrient contents of the eating plan of two models from the DASH nutrients' tolerable target level for 2000 calorie and $1500 \mathrm{mg}$ sodium daily levels as shown in Table 1 , we saw that there is minimized deviation from the DASH diet's tolerable intake levels using the Weighted Goal Programming DASH diet model than when the Linear Programming DASH diet model is used. As shown in the comparison, in the Weighted GP DASH diet model only has deviation of $2.7 \%$ only in the fiber content whereas in the diet plan of the LP DASH model there were large deviations of some nutrients from their targeted DASH tolerable intake level. As shown, there was 63.5\%, 18.6\%, 79.1\%, 52.8\%, 166.9\% and $80.1 \%$ nutrient content deviation for total fat, sodium, cholesterol, saturated fat, fiber and potassium respectively from their DASH tolerable target level which is enormous. Such is also the case in Table 2 in the comparison for other calorie levels. Hence, we can conclude that the Weighted Goal Programming DASH diet model is a better model in obtaining a daily diet plan that minimizes the deviations from the DASH tolerable intake nutrient levels at desired cost than the LP DASH diet model.

\section{References}

[1] National Heart, Lung and Blood Institute (2006) Your Guide to Lowering Your Blood Pressure with DASH. NIH Publication.

[2] Iwuji, A.C., Nnanna, M. and Ndulue, N.E.C. (2016) An Optimal DASH Diet Model for People with Hypertension Using Linear Programming Approach. Open Journal of Optimization, 5, 14-21. https://doi.org/10.4236/ojop.2016.51002

[3] Bhargara, A.K., Bansal, D., Chandramouli, A.B. and Kumar, A. (2011) Weighted Goal programming Model Formulation and Calculation of Diet Planning. Interna- 
tional Transactions in Mathematical Sciences \& Computer, 4, 123-130.

https://doi.org/10.4236/ajor.2014.42007

[4] Orumie, U.C. and Ebong, D. (2014) A Glorious Literature on Linear Goa Programming Algorithms. American Journal of Operations Research, 4, 59-71.

[5] Ignizio, J.P. (1978) A Review of Goal Programming: A Tool for Multi-Objective Analysis. The Journal of the Operational Research Society, 29, 1109-1119. https://doi.org/10.1057/jors.1978.243

[6] Gupta, P.K. and Hira, D.S. (2012) Operations Research. S. Chand and Company Ltd., New Delhi.

[7] Anderson, A.M. and Earle, M.D. (1983) Diet Planning in the Third World by Linear and Goal Programming. The Journal of the Operational Research Society, 34, 9-16. https://doi.org/10.1057/jors.1983.2

[8] Ferguson, E.L., Darmon, N., Fahmida, U., Fitrivanti, S., Harper, T.B. and Premachandra, I.M. (2006) Design of Optimal Food-Based Complementary Feeding Recommendation and Identification of Key "Problem Nutrients" Using Goal Programming. Journal of Nutrition, 136, 2399-2404.

[9] Omotesho, O.A. and Muhammad-Lawal, A. (2010) Optimal Food Plan for Rural Households' Food Security in Kwara State Nigeria: The Goal Programming Approach. Journal of Agricultural Biotechnology and Sustainable Development, 2, 101-104. http://www.academicjournals.org/JABSD

[10] Pasic, M., Catovic, A., Bijelonja, I. and Bahtanovic, A. (2013) Weighted Goal Programming Optimization Model. Journal of Trends in the Development of Machinery and Associated Technology, 17, 101-104.

[11] Gerdessen, J.C. and de Vries, J.H.M. (2015) Diet Models with Linear Goal Programming: Impact of Achievement Function. European Journal of Clinical Nutrition, 69, 1272-1278. https://doi.org/10.1038/ejcn.2015.56

[12] Eghbali, H., Eghbali, M.A. and Vahidian, K.A. (2012) Optimizing Human Diet Problem Based on Price and Taste using Multi-Objective Fuzzy Linear Programming Approach. Ijocta, 2, 1-9. https://doi.org/10.11121/ijocta.01.2012.0095

[13] Zgajnar, J., Erjavec, E. and Kavcic, S. (2008) Multi-Step Beef Ration Optimization: Application of Linear and Weighted Goal Programming with a Penalty Function. Agricultural and Food Science, 3, 193-206.

[14] Pikes, T. and Adams, R. (2016) Computational Nutrition: An Algorithm to Generate a Diet Plan to Meet Specific Nutritional Requirements. E-Health Telecommunication Systems and Networks, 5, 31-38. https://doi.org/10.4236/etsn.2016.52004

[15] Hurwicz, M.-L. and Rose, M. (2016) Older Adults' Explanatory Models of High Blood Pressure. Health, 8, 680-693. https://doi.org/10.4236/health.2016.87072

[16] Arraut-Berilo, A., Delalic, A. and Huseinbasic (2017) A Nutritional Analysis of the Food Basket of BiH: A Linear Programming Approach. South East European Journal of Economics and Business, 12, 104-113.

[17] Charnes, A. and Cooper, W.W. (1975) Goal Programming and Multiple Objective Optimizations. Center for Cypernetic Studies Report CCS-250, the University of Texas Austin.

[18] Ragsdale, C.T. (2007) Spreadsheet Modeling and Deision Analysis: A Practical Introduction to Management Sciences. 5th Edition, South Western. 


\section{Appendices}

1) Formulated weighted goal programming model for 2000 calorie a day eating plan with $1500 \mathrm{mg}$ sodium level

$$
\begin{aligned}
\text { Minimize } D= & (1) \frac{d_{C}^{+}}{944} \cdot \frac{100}{1}+(1) \frac{d_{S}^{+}}{1500} \cdot \frac{100}{1}+(1) \frac{d_{c o l}^{+}}{129} \cdot \frac{100}{1}+(1) \frac{d_{T F}^{+}}{68} \cdot \frac{100}{1} \\
& +(1) \frac{d_{S F}^{+}}{16} \cdot \frac{100}{1}+(1) \frac{d_{M}^{-}}{542} \cdot \frac{100}{1}+(1) \frac{d_{F i b}^{-}}{34} \cdot \frac{100}{1}+(1) \frac{d_{P}^{-}}{4721} \cdot \frac{100}{1} \\
& +(1) \frac{d_{C a l}^{-}}{1334} \cdot \frac{100}{1}+\left((1) \frac{d_{\text {calo }}^{-}}{2000}+(1) \frac{d_{c a l o}^{+}}{2000}\right) \cdot \frac{100}{1}
\end{aligned}
$$

Subject to the constraints

$$
\begin{aligned}
& 15 x_{1}+20 x_{2}+15 x_{3}+15 x_{4}+30 x_{5}+15 x_{6}+15 x_{7} \\
& +50 x_{8}+(0) d_{c}^{-}+(1) d_{c}^{+}=944 \text { Naira }
\end{aligned}
$$

(Cost goal constraint in Naira)

$$
\begin{aligned}
& 33.6 x_{1}+1.5 x_{2}+124.8 x_{3}+15 x_{4}+8.1 x_{5}+3.2 x_{6} \\
& +2.4 x_{7}+73 x_{8}+(0) d_{s}^{-}-(1) d_{s}^{+}=1500 \mathrm{mg}
\end{aligned}
$$

(Sodium goal constraint in grams)

$$
3 x_{5}+0.29 x_{8}+(0) d_{c o l}^{-}-(1) d_{c o l}^{+}=129 \mathrm{mg}
$$

(Cholesterol goal constraint in milligrams)

$$
\begin{aligned}
& 0.24 x_{1}+11.48 x_{2}+0.58 x_{3}+0.30 x_{4}+0.10 x_{5}+0.48 x_{6} \\
& +0.16 x_{7}+4.1 x_{8}+(0) d_{f}^{-}-(1) d_{f}^{+}=68 g
\end{aligned}
$$

(Total fat goal constraint in grams)

$$
\begin{aligned}
& 0 x_{1}+1.55 x_{2}+0.2 x_{3}+0 x_{4}+0.6 x_{5}+0 x_{6} \\
& +0 x_{7}+34 x_{8}+(0) d_{s f}^{-}-(1) d_{s f}^{+}=16 \mathrm{~g}
\end{aligned}
$$

(Saturated fat goal constraint in milligrams)

$$
\begin{aligned}
& 9.6 x_{1}+47.75 x_{2}+13.25 x_{3}+14 x_{4}+2.4 x_{5}+17.6 x_{6} \\
& +8 x_{7}+43 x_{8}+(1) d_{\text {mag }}^{-}-(0) d_{\text {mag }}^{+}=542 \mathrm{mg}
\end{aligned}
$$

(Magnesium goal constraint in milligrams)

$$
\begin{aligned}
& 2.48 x_{1}+2.33 x_{2}+1.55 x_{3}+3 x_{4}+0 x_{5}+2.72 x_{6} \\
& +0.24 x_{7}+0 x_{8}+(1) d_{f i b}^{-}-(0) d_{f i b}^{+}=34 \mathrm{~g}
\end{aligned}
$$

(Fiber goal constraint in grams)

$$
\begin{aligned}
& 212.8 x_{1}+181.75 x_{2}+56.5 x_{3}+264 x_{4}+31 x_{5}+265.6 x_{6} \\
& +87.2 x_{7}+397 x_{8}+(1) d_{P}^{-}-(0) d_{P}^{+}=4721 \mathrm{mg}
\end{aligned}
$$

(Potassium goal constraint in milligrams)

$$
\begin{aligned}
& 28 x_{1}+4.25 x_{2}+12.25 x_{3}+24 x_{4}+25 x_{5}+49.6 x_{6} \\
& +5.6 x_{7}+40 x_{8}+(1) d_{\text {Cal }}^{-}-(0) d_{\text {Cal }}^{+}=1334 \mathrm{mg}
\end{aligned}
$$


(Calcium goal constraint in milligrams)

$$
\begin{aligned}
& 28 x_{1}+144.5 x_{2}+58.5 x_{3}+90 x_{4}+7 x_{5}+72 x_{6}+23.2 x_{7} \\
& +151 x_{m}+(0) d_{\text {calo }}^{-}+(1) d_{\text {calo }}^{+}=2000 \text { calories }
\end{aligned}
$$

(Calorie goal Constraint).

2) Linear Programming DASH diet model for 2000 calorie and $1500 \mathrm{mg}$ sodium levels a day eating plan.

Minimize $D C=15 X_{1}+20 X_{2}+15 X_{3}+15 X_{4}+30 X_{5}+15 X_{6}+15 X_{7}+50 X_{8}$ Subject to the constraints

$0.24 X_{1}+11.48 X_{2}+0.58 X_{3}+0.30 X_{4}+0.10 X_{5}+0.48 X_{6}+0.16 X_{7}+4.1 X_{8} \leq 68$

(Constraint on total fat)

$$
33.60 X_{1}+1.5 X_{2}+124.8 X_{3}+15 X_{4}+8.1 X_{5}+3.2 X_{6}+2.4 X_{7}+73 X_{8} \leq 1500
$$

(Constraint on sodium)

$$
0 X_{1}+0 X_{2}+0 X_{3}+0 X_{4}+3 X_{5}+0 X_{6}+0 X_{7}+0.29 X_{8} \leq 129
$$

(Constraint on cholesterol)

$$
0 X_{1}+1.55 X_{2}+0.2 X_{3}+0 X_{4}+0.6 X_{5}+0 X_{6}+0 X_{7}+340 X_{8} \leq 16
$$

(Constraint on saturated fat)

$$
28 X_{1}+4.25 X_{2}+12.25 X_{3}+24 X_{4}+250 X_{5}+49.6 X_{6}+5.6 X_{7}+40 X_{8} \geq 1334
$$

(Constraint on calcium)

$$
9.6 X_{1}+47.75 X_{2}+13.25 X_{3}+14 X_{4}+2.4 X_{5}+17.6 X_{6}+8 X_{7}+43 X_{8} \geq 542
$$

(Constraint on magnesium)

$$
2.48 X_{1}+2.33 X_{2}+1.55 X_{3}+3 X_{4}+0 X_{5}+2.72 X_{6}+0.24 X_{7}+0 X_{8} \geq 34
$$

(Constraint on fiber)

$$
212.8 X_{1}+181.75 X_{2}+56.5 X_{3}+264 X_{4}+31 X_{5}+262.6 X_{6}+87.2 X_{7}+397 X_{8} \geq 4721
$$

(Constraint on potassium)

$$
20 X_{1}+144.5 X_{2}+58.5 X_{3}+90 X_{4}+7 X_{5}+72 X_{6}+23.2 X_{7}+151 X_{8}=2000
$$

(Constraint on calorie)

$$
\begin{aligned}
& X_{1} \geq 4 \\
& X_{2} \leq 1 \\
& X_{3} \geq 3 \\
& X_{4} \geq 4 \\
& X_{5} \geq 6 \\
& X_{6} \geq 4 \\
& X_{7} \geq 4 \\
& X_{8} \leq 6 \\
& X_{1} \leq 20
\end{aligned}
$$




$$
\begin{aligned}
& X_{3} \leq 8 \\
& X_{4} \leq 6 \\
& X_{5} \leq 9 \\
& X_{6} \leq 8 \\
& X_{7} \leq 9
\end{aligned}
$$

\begin{tabular}{|c|c|c|c|c|c|c|c|c|}
\hline \multirow[b]{2}{*}{ Nutrients } & \multicolumn{8}{|c|}{ F FOODS } \\
\hline & Carrot & $\begin{array}{c}\text { Ground } \\
\text { nut } \\
\text { (cooked) }\end{array}$ & $\begin{array}{l}\text { Bread } \\
\text { (whole } \\
\text { wheat) }\end{array}$ & $\begin{array}{l}\text { Sweet } \\
\text { potato } \\
\text { (boiled) }\end{array}$ & $\begin{array}{c}\text { Milk } \\
\text { (low fat) }\end{array}$ & Orange & $\begin{array}{l}\text { Water } \\
\text { melon }\end{array}$ & $\begin{array}{c}\text { Fish } \\
\text { (grilled) }\end{array}$ \\
\hline $\begin{array}{c}\text { Total } \\
\text { Fat }\end{array}$ & 0.24 & 11.48 & 0.58 & 0.30 & 0.10 & 0.48 & 0.16 & 4.10 \\
\hline Sodium & 33.60 & 1.50 & 124.80 & 15.00 & 8.10 & 3.20 & 2.40 & 73.00 \\
\hline Cholesterol & 0 & 0 & 0 & 0 & 3.00 & 0 & 0 & 0.29 \\
\hline $\begin{array}{c}\text { Saturated } \\
\text { Fat }\end{array}$ & 0 & 1.55 & 0.20 & 0 & 0.60 & 0 & 0 & 34.00 \\
\hline Calcium & 28.00 & 4.25 & 12.25 & 24.00 & 25.00 & 49.60 & 5.60 & 40.00 \\
\hline Magnesium & 9.60 & 47.75 & 13.25 & 14.00 & 2.40 & 17.60 & 8.00 & 43.00 \\
\hline Fiber & 2.48 & 2.33 & 1.55 & 3.00 & 0 & 2.72 & 0.29 & 0.00 \\
\hline Potassium & 212.8 & 181.75 & 56.50 & 264.0 & 31.0 & 265.6 & 87.2 & 549.0 \\
\hline Calorie & 28 & 144.50 & 58.5 & 90.00 & 7.00 & 72.0 & 23.2 & 151.00 \\
\hline $\begin{array}{l}\text { Weight per } \\
\text { serving } \\
\text { of food } \\
\text { (in grams) }\end{array}$ & $80 \mathrm{~g}$ & $25 \mathrm{~g}$ & $25 \mathrm{~g}$ & $100 \mathrm{~g}$ & $20 \mathrm{~g}$ & $160 \mathrm{~g}$ & $80 \mathrm{~g}$ & $100 \mathrm{~g}$ \\
\hline $\begin{array}{l}\text { Cost of per } \\
\text { serving of } \\
\text { food }\end{array}$ & $\mathrm{N} 15$ & $\mathrm{~N} 20$ & $\mathrm{~N} 15$ & $\mathrm{~N} 15$ & $\mathrm{~N} 30$ & $\mathrm{~N} 15$ & $\mathrm{~N} 15$ & $\mathrm{~N} 50$ \\
\hline
\end{tabular}

\begin{tabular}{|c|c|c|c|c|}
\hline \multirow{2}{*}{ Gender } & \multirow{2}{*}{ Age } & \multicolumn{3}{|c|}{ Calories needed for each activity level } \\
\hline & & Sedentary & Moderately active & Active \\
\hline \multirow{3}{*}{ Female } & $19-30$ & 2000 & $2000-2200$ & 2400 \\
\hline & $31-50$ & 1800 & 2000 & 2200 \\
\hline & $51+$ & 1600 & 1800 & $2000-2200$ \\
\hline \multirow{3}{*}{ Male } & $19-30$ & 2400 & $2600-2800$ & 3000 \\
\hline & $31-50$ & 2200 & $2400-2600$ & $2800-3000$ \\
\hline & $51+$ & 2000 & $2200-2400$ & $2400-2800$ \\
\hline
\end{tabular}

3) Table showing sample foods together with their nutrient composition, weigh (in Grams) and cost for a serving size.

4) DASH daily calorie need chart for different level of activities 
5) Tolerable target intake level of DASH nutrients for 1500 milligrams sodium level and 2000 calories a day DASH eating plan

\begin{tabular}{llllllllll}
\hline Nutrients Sodium Calorie & $\begin{array}{c}\text { Total Saturated } \\
\text { fat }\end{array}$ & fat & Cholesterol Calcium & Magnesium Potassium & Fiber \\
\hline Daily level $1500 \mathrm{mg}$ & 2000 & $68 \mathrm{~g}$ & $16 \mathrm{~g}$ & $129 \mathrm{mg}$ & $1334 \mathrm{mg}$ & $542 \mathrm{mg}$ & $5471 \mathrm{mg}$ & $34 \mathrm{~g}$ \\
\hline
\end{tabular}

Submit or recommend next manuscript to SCIRP and we will provide best service for you:

Accepting pre-submission inquiries through Email, Facebook, LinkedIn, Twitter, etc. A wide selection of journals (inclusive of 9 subjects, more than 200 journals)

Providing 24-hour high-quality service

User-friendly online submission system

Fair and swift peer-review system

Efficient typesetting and proofreading procedure

Display of the result of downloads and visits, as well as the number of cited articles

Maximum dissemination of your research work

Submit your manuscript at: http://papersubmission.scirp.org/

Or contact ajor@scirp.org 